\title{
VIDEOGRAVAÇÃO EM SALA DE AULA
}

\section{A videogravação em sala de aula auxilia a pesquisa e a formação de professores, além de abrir caminho para novos experimentos através do uso de tecnologias próprias dos meios de comunicação nos processos educacionais}

A Lei de Diretrizes e Bases, em tramitação no Senado, afirma que o conteúdo curricular, do primeiro ao terceiro grau, deve, entre outras coisas, incluir a iniciação sobre a tecnologia e a leitura crítica dos meios de comunicação. Essa iniciação pressupõe que a escola terá atividades que envolvam o uso de equipamentos durante suas aulas. Tais atividades exigirão dos professores um conhecimento, no mínimo básico, sobre os diferentes instrumentos e suas respectivas linguagens. Esse conhecimento seria passado aos futuros professores pelas universidades.

Algumas iniciativas já se antecipam à aprovação do Senado como, por exemplo, a Faculdade de Comunicação Anhembi-Morumbi que já oferece o curso de Comunicação Educacional. Na Escola de Comunicações e Artes da USP, o Departamento de Comunicações e Artes/CCA está propondo uma licenciatura em Comunicação e Educação. A Faculdade de Educação da USP-

\section{O AUTOR}

\section{Vicente Gosciola}

Mestre em Ciência da Comunicação pela ECAUSP. Co-ministra a disciplina Teoria e Métodos da Pesquisa em Comunicação na ECA-USP e é professor de Tecnologia Educacional da Universidade Paulista-UNIP.
FEUSP oferece no curso de Pedagogia a disciplina Educação e Meios de Comunicação, ministrada pela $\operatorname{Prof}^{\mathrm{a}} \mathrm{Dr}^{\mathrm{a}}$ Mariazinha Felisminda de Rezende e Fusari. Na Universidade Paulista-UNIP venho ministrando a disciplina Tecnologia Educacional no curso de Pedagogia. São essas, entre outras iniciativas no terceiro grau, algumas tentativas na direção de um florescimento de profissionais da educação sintonizados com a nova realidade do ensino no país.

A FEUSP, há muito tempo, vem utilizando o recurso audiovisual como uma importante ferramenta de estudos. A videocâmera vem sendo utilizada não só pela professora Mariazinha como também por muitos outros professores. Os registros produzidos em vídeo servem, principalmente, para dois tipos de estudos: a pesquisa sobre o desenvolvimento cognitivo e o aperfeiçoamento da prática pedagógica dos futuros professores. Como responsável pela área de vídeo da FEUSP realizamos todas as videogravações das aulas a serem estudadas. Em função desses oito anos de trabalho contínuo em videogravação, desenvolvemos algumas técnicas e consideramos que seria interessante confrontar com outras experiências de outros profissionais da área como também com teorias relacionadas com o assunto. Para tanto desenvolvemos a dissertação que tem como título Nos Bastidores da Sala de Aula: a videogravação no processo 
de ensino-aprendizagem ${ }^{1}$. Investigamos a técnica e a metodologia das gravações através de prismas teóricos referentes à percepção, ao filme etnográfico e à linguagem cinematográfica.

\section{VIDEOGRAVAÇÃO NA PESQUISA}

É fato que não se deve mais descuidar da videogravação. Ela pode significar para o pesquisador de processos educacionais uma fonte de registros, imagens e sons, muito fidedignos. As videogravações têm que ser boas e para tanto existem conceitos e técnicas que podem ser adaptadas a esta atividade, propondo um diálogo com professores e pesquisadores atentos a essa tecnologia. Nosso esforço se dirigiu exatamente ao estudo das técnicas da gravação de aulas, de como fazer as gravações, o que também não encontramos, em toda nossa pesquisa, em nenhum tratado técnico de estudiosos das áreas do cinema e do vídeo.

Nestes quase oito anos de atividade como realizador de videogravação de aulas, temos questionado tudo o que fazemos. Tomadas, expressões registradas e não registradas - tanto significativas quanto não significativas-, sequiências de close-ups, panorâmicas em plano aberto, nível de luz, nível de áudio, posicionamento de câmera, tudo isso e muito mais vem sendo constantemente analisado. Durante esse período atuamos em duas áreas simultaneamente: vídeo e educação. Para tentar contemplar as duas áreas igualmente, nos apoiamos em teóricos diversos.

Howard Gardner ${ }^{2}$, professor de Neurologia na Boston University School of Medicine, EUA, questiona o conceito tradicional de inteligência e o teste de Q.I., estando para isso baseado na teoria das múltiplas inteligências. Ele toma o cuidado de afirmar que as múltiplas inteligências são interligadas, mais de sete, e são desenvolvidas de maneira relativamente autônoma e diferenciada para cada indivíduo. Essa teoria serviu como guia de investigação das capacidades físicas e psíquicas utilizadas em atividades de captação de imagens.

Contrapondo os conceitos que Gardner elaborou para a teoria do aprendizado com as experiências da FEUSP no setor, pode-se dizer que a atividade de observação de uma aula requer habilidades de certos campos da mente.

O lingüístico é necessário para uma boa compreensão do que se passa em termos de conteúdo durante uma aula. $\mathrm{O}$ intrapessoal é exigido para que as observações sejam feitas da maneira mais completa possível, com reflexões silenciosas, sem perturbar o andamento da aula. O visual-espacial é imprescindível para que se apure rapidamente a localização do sujeito a ser observado e para que seus gestos e expressões sejam facilmente reconhecidos. O musical tem destaque, pois é necessário para um claro entendimento do que se fala, e do tom em que se desenrolam os diálogos. Para o operador da câmera, ou o realizador do vídeo, todas as habilidades acima citadas são totalmente imprescindíveis.

O pesquisador necessita encontrar no videoteipe tomadas completas que permitam rever todas as informações que observou durante a gravação e as tomadas que apresentem informações que só a câmera foi capaz de captar. Durante a gravação alguns eventos muito significativos para a pesquisa são registrados, mas não podem ser observados pelo pesquisador.

$\mathrm{O}$ videoteipe, por possibilitar que se assista muitas vezes a uma mesma tomada, permite

1. GOSCIOLA, Vicente. Nos bastidores da sala de aula: a videogravação no processo de ensino-aprendizagem. São Paulo: ECA-USP, 1995 (Dissertação de Mestrado).

2. GARDNER, Howard. Estruturas da mente: a teoria das inteligências múltiplas. 1.ed. Porto Alegre: Artes Médicas Sul, 1994. 
que se descubram fatos impossíveis de se constatar ao vivo, pela própria condição de uma sala de aula onde acontecem infinitas coisas ao mesmo tempo.

Além dos quatro campos da mente já citados, outros são imprescindíveis para o realizador do vídeo. O lógico-matemático está presente para que a operação da câmera esteja sincronizada com os eventos a serem gravados, operações como foco e movimentos de câmera devem estar acompanhando tudo o que acontece durante a aula. $\mathrm{O}$ interpessoal é usado pelo realizador para que possa relacionar-se bem com professor e alunos, dando tranqüilidade a eles de forma que não se sintam intimidados pela sua presença e para que tenha boa previsibilidade do que virá a acontecer num ambiente de interação grupal como é o de uma sala de aula. O corpo-cinestésico é o que permite ao realizador se antecipar a qualquer evento durante a aula, a partir do conhecimento que ele tem de como as pessoas prenunciam uma participação, como, por exemplo, o endireitar da coluna seguido de um abrir da expressão facial quase iniciando a fala.

Uma outra habilidade muito exigida neste campo é a de facilmente poder movimentar a câmera enquanto olha para o funcionamento da mesma, enquanto olha para o viewfinder, visor da câmera, para saber o que está sendo gravado e enquanto olha para o que acontece na classe, para se preparar para um novo posicionamento e uma nova tomada. "Tudo ao mesmo tempo agora".

\section{APURAR OS SENTIDOS}

Outro autor, Rudolf Arnheim ${ }^{3}$, professor do Departamento de Estudos Visuais e Ambientais da Harward University, EUA, desenvolveu obras, já consideradas clássicas pela sua importância, sobre a percepção visual ligada à arte e à psicologia, das quais aproveitamos a sistematização das idéias sobre com- posição e configuração de imagens para analisar as condições de enquadramento.

O realizador não faria uma boa cobertura da aula se procurasse captar toda a sequiência de funções, descritas acima, através apenas da interação entre um único aluno e o professor. Perderia as demais interações entre os outros alunos e o professor ou entre alunos e alunos. Há muita coisa acontecendo ao mesmo tempo durante a aula e o pesquisador sempre necessitará do maior número de dados possível, mesmo que a pesquisa tenha um único e simples objetivo.

É preciso, então, abrir ainda mais o leque de percepção para a captação com a câmera de vídeo. Talvez, mais que os olhos, abrir os poros da pele. Sentir tudo o que acontece em sala de aula. É indispensável ver a aula como um todo composto de elementos inseparáveis.

$\mathrm{O}$ todo apresentado, conforme Arnheim, constitui uma configuração, a gestalt. O realizador sente com todos os sentidos o que se passa. Pode assim perceber o que acontece na aula e, então, gravar o que está configurado. Os diversos sujeitos de uma aula apresentam movimentos e intenções, determinando o que acontece e o que vai acontecer de importante durante a aula. Para Rudolf Arnheim a análise perceptiva aprimora a visão para a tarefa de penetrar no objeto de estudo "até os limites mais impenetráveis".

A partir daí, é possível fazer algumas observações, principalmente quanto aos padrões estruturais que se apreendem e quais os mecanismos perceptivos ativados para a videogravação de uma aula. Duas idéias chamam a atenção: a primeira se relaciona com a idéia de que durante as videogravações sempre estará sendo alterada a realidade. Arnheim, para embasar esta idéia, cita Ethel Puffer - "interesse intrínseco afetando o peso compositivo"- e completa indicando

3. ARNHEIM, Rudolf. Arte e percepção visual: uma psicologia da visão criadora. 7.ed. São Paulo: Pioneira, 1992. 
que experiências atuais sugerem que a "percepção pode também ser influenciada pelos desejos e temores do observador", assim como por seus conhecimentos.

Assim, a videogravação apresenta não a inexistência da realidade, mas uma outra realidade, que talvez satisfaça a uma pesquisa. As realidades - a da aula em si, a que apreende o realizador e a que chega ao entendimento do pesquisador ao assistir à videogravação - podem ter pontos em comum. Esses pontos em comum são fatores determinantes da pesquisa. Cada visão, como criadora da realidade, dá sua contribuição efetiva, resultando numa pesquisa pontilhada por subjetivismo, já que "toda percepção é também pensamento".

Quanto à segunda idéia, "raciocínio também é intuição", a experiência de videogravação de aulas na FEUSP permite afirmar que a intuição é uma habilidade muito exigida do realizador durante a videogravação de uma aula. Requer prontidão para sentir qualquer alteração no ambiente, gravando-a exatamente no momento em que ela acontecer. Por isso, enxergar o evento aula como um todo tem sido prioridade número um na lista de atitudes para a realização de videogravações. Se o realizador estiver com a câmera sempre em plano aberto, por exemplo, no todo da ação da aula, perderá os detalhes. Esses detalhes podem ser vistos por quem está assistindo à aula, mas quem for assistir à videogravação posteriormente, certamente não verá detalhes como expressões faciais ou mesmo as tentativas de fazer uso da palavra por parte de algum aluno.

Outra fonte teórica vem de Frederick Erickson e Jan Wilson ${ }^{4}$, ambos do Institute for Research on Teaching College of Education Michigan State University, EUA. Eles tratam dos resultados teóricos de filmagens e videogravações do dia-a-dia das escolas dos Estados Unidos do ponto de vista etnológico, que auxiliam na concepção de operação de câmera para registros etnográficos em situações de ensino-aprendizagem.

É importante também o trabalho de Marcel Martin ${ }^{5}$, ensaísta e crítico de cinema francês. Ele define as características principais e a linguagem da imagem fílmica, as quais utilizamos para tentar estabelecer um paralelo com a linguagem videográfica nos registros de eventos educacionais. Relacionamos os elementos: elipse, sinédoque, planos (os mais utilizados em videogravações de aulas: plano geral, plano médio, plano americano e close-up), ângulos (os mais utilizados: "plongée" — câmera registra o sujeito abaixo dela, isto é, de cima para baixo-e "contra-plongée" —câmera registra o sujeito acima dela, isto é, de baixo para cima); profundidade de campo, movimentos de câmera (os mais utilizados: "zoom in", "zoom out" e panorâmica) e plano-seqüência.

\section{ACESSO ÀS TÉCNICAS}

Conforme José Geraldo Couto, "a guerra pelo mercado consumidor de produtos audiovisuais vai ser uma das mais cruciais do fim do século"6. $\mathrm{O}$ assunto que tem despertado mais interesse nesta área é o papel criador da câmera.

A iluminação, as lentes, os ângulos, os movimentos e os enquadramentos produzem uma imagem que passa a ser a única realidade visível para o espectador. A câmera figura, aqui, como a geradora de uma realidade própria.

Não é para a iluminação especificamente, nem para as lentes, nem para nenhuma das

4. ERICKSON, Frederic, WILSON, Jan. Sights and sounds of life in schools: a resource guide to film and videotape for education. (Imagens e sons da vida nas escolas: um manual de filme e vídeo para a educação) Michigan, Institute for Research on Teaching of the College of Education at Michigan State University, 1982.

5. MARTIN, Marcel. A linguagem cinematográfica. São Paulo: Brasiliense, 1985.

6. Folha de S.Paulo. $1^{\circ}$ de janeiro de 1994. 
outras técnicas individualmente que o desenvolvimento da imagem aponta, mas sim para o entendimento do todo da imagem em movimento; para que a sua complexidade seja inteligível, para que o videoteipe, como resultado de uma gravação de um evento, fique cada vez mais próximo de sua origem. Um videoteipe bem realizado pelo realizador e bem interpretado pelo pesquisador permite que se possa estar muito próximo do real. Nesse esforço comum eles caminham para compreender a complexidade da imagem em movimento.

Os avanços nesta área permitem uma apreensão muito mais ampla do que se passa em ambientes de ensino-aprendizagem. A videogravação de uma aula é uma fonte riquíssima para as mais diversas pesquisas, pois o videoteipe apresenta um acúmulo de vários dados simultâneos. É um registro de informações claras que se aproxima do evento original. Um mesmo pesquisador pode observar inúmeros conteúdos, distintamente, bastando apenas voltar a fita e assistir a ela de novo com um outro interesse. Pelo videoteipe um evento pode ser assistido repetidas vezes. As diversas possibilidades de leitura de uma mesma cena e o acesso à pluralidade de objetos de análise são propósitos que contemplam a pesquisa etnográfica.

Não é só o acesso à pluralidade de objetos que interessa ao pesquisador de processos de ensino-aprendizagem. Ele sente a necessidade de uma videogravação com detalhes e precisão em suas tomadas. Ela deve ser clara, não pode ter problemas de iluminação, áudio, enquadramento etc. Não pode desperdiçar expressões de alunos ou professores que sejam indícios significativos para a pesquisa. Quem está operando a câmera deve se lembrar, entre outras coisas, que sua leitura é um filtro ou um recorte da realidade, a qual será refiltrada pela câmera e que será refiltrada novamente pelo aparelho de $\mathrm{TV}$, antes de ser lida, refiltrada, várias vezes pelo pesquisador.
Ao tomar conhecimento do alcance de aplicação da videogravação de eventos educacionais, fica impossível deixar de encarar, com no mínimo uma certa curiosidade, sua tecnologia.

Ainda que os pesquisadores não tenham conhecimentos mais complexos da técnica, podem realizar bons trabalhos em videogravação. Por terem conhecimento do objetivo do projeto, são capazes de captar imagens de grande riqueza de informações para a pesquisa.

Mesmo que a câmera balance um pouco, mesmo que o foco demore a ser corrigido, mesmo que a iluminação não seja suficiente, a gravação apresentará acontecimentós certeiros, diretamente ligados ao interesse da investigação.

Mas não se pode desperdiçar oportunidades e, para tanto, seria importante que o pesquisador, realizador de uma videogravação, fosse treinado antecipadamente ou, então, que o vídeo-realizador especializado tomasse conhecimento de tudo o que possa acontecer e interessar à pesquisa $\mathrm{e}$, principalmente, onde quer chegar a pesquisa, qual o seu objetivo central. Sem isso, esse profissional poderia captar as cenas com alta qualidade de imagem mas, como resultado final, a fita poderia apresentar apenas cenas mais genéricas, sem a profundidade desejável.

É possível encontrar um meio termo entre realizador e pesquisador. Pode-se desenvolver uma técnica de operação de câmera de vídeo própria para pesquisas educacionais. E, quanto maior for o alcance desta tecnologia, mais abrangente será o leque de áreas de investigação.

A investigação da prática de videogravação de eventos educacionais pertence ao campo da interdisciplinaridade. Segue, não por modismo mas por necessidade concreta, uma tendência mundial de convergir pontos de vista diversos para um único objeto de 
estudo. É curioso observar como duas áreas do conhecimento podem ser tão próximas quanto ao âmbito de sua ação e quanto a seus destinatários e, ao mesmo tempo, tão distantes quanto ao método de trabalho e os resultados alcançados.

Quando se cogita criar um produto em conjunto entre as áreas de Educação e de Comunicação o resultado nem sempre é dos mais satisfatórios. Por exemplo, um vídeo educativo produzido por uma emissora de televisão ou produtora de vídeo (Telecurso 2000, Fundação Roberto Marinho/Marcelo Tas) apresentou problemas de roteiro, ainda que assessorada por professores especialistas. O que também acontece com os especialistas em Educação (Um salto para o futuro da Fundação Roquete Pinto, TVE-RJ, teve problemas no tempo e na dinâmica de apresentação) mesmo que apoiados por profissionais de televisão.

Invariavelmente, o resultado final tem sido incompatível com uma programação de televisão que desenvolve um formato próprio, bem elaborado, bem acabado e perfeitamente sintonizado com sua clientela, que, em grande maioria, são os próprios educandos. Investigar onde está o elo perdido, a razão pela qual as duas áreas não dialogam, apesar dos esforços louváveis, são preocu- pações muito importantes, e para as quais tentamos trazer alguma contribuição.

Estão aqui, portanto, algumas reflexões desenvolvidas através da nossa prática e pelas nossas leituras a respeito do assunto videogravar aulas. Temos certeza de que se trata apenas de um pequeno começo, mas consolida o desejo de fazer melhor.

Videogravar bem uma aula não é a mesma coisa que videogravar bem uma festa de aniversário ou um casamento. Também não é ter na cabeça uma ordenação pré-determinada sobre o que perseguir.

É o vídeo-realizador retirar de si a imagem de persecutor diante da pessoa a ser registrada. É estar sensível a qualquer evento que possa ter um significado importante, um silêncio, uma respiração, um movimento espiralado da coluna de quem se prepara para falar, um olhar introspectivo. As reflexões aqui apresentadas não esgotam nem explicam todos os pontos que constituem a atividade de videogravar aulas; elas devem prosseguir para proporcionar novas discussões, respondendo a um número cada vez maior de questionamentos que, sem dúvida, surgirão em função da crescente demanda que se faz desta atividade. 